Check for updates

Cite this: RSC Adv., 2018, 8, 14870

Received 12th October 2017

Accepted 9th April 2018

DOI: 10.1039/c7ra11245a

rsc.li/rsc-advances

\section{Effective solvent-free oxidation of cyclohexene to allylic products with oxygen by mesoporous etched halloysite nanotube supported $\mathrm{Co}^{2+} \uparrow$}

\begin{abstract}
Cuiping Li, iD * Yue Zhao, Tianwen Zhu, Yan'ge Li, Jiajia Ruan and Guanghui Li
One dimensional mesoporous etched halloysite nanotube supported $\mathrm{CO}^{2+}$ is achieved by selective etching of $\mathrm{Al}_{2} \mathrm{O}_{3}$ from halloysite nanotube $(\mathrm{HA})$ and immersing the etched $\mathrm{HA}(\mathrm{eHA})$ into the $\mathrm{Co}\left(\mathrm{NO}_{3}\right)_{2} \cdot 6 \mathrm{H}_{2} \mathrm{O}$ solution consecutively. By facilely tuning the etching time and the weight ratio of $\mathrm{Co}\left(\mathrm{NO}_{3}\right)_{2} \cdot 6 \mathrm{H}_{2} \mathrm{O}$ to eHA, the morphology, specific surface area and the supported $\mathrm{Co}^{2+}$ content of the mesoporous material can be tuned. The method for mesoporous material is scaled up and can be extended to other clay minerals. The mesoporous eHA supported $\mathrm{Co}^{2+}$ is used as catalyst for the selective catalytic oxidation of cyclohexene in solvent-free reaction system with $\mathrm{O}_{2}$ as oxidant. The results shows the catalytic activity is dependent on etching time, weight ratio of $\mathrm{Co}\left(\mathrm{NO}_{3}\right)_{2} \cdot 6 \mathrm{H}_{2} \mathrm{O}$ to eHA, calcination treatment and reaction time/temperature. Among them, mesoporous eHA supported $\mathrm{Co}^{2+}$ prepared with $18 \mathrm{~h}$ etching time and $2: 1 \mathrm{Co}\left(\mathrm{NO}_{3}\right)_{2} \cdot 6 \mathrm{H}_{2} \mathrm{O} / \mathrm{eHA}$ weight ratio without calcination $\left(\mathrm{HA} / \mathrm{HCl}-18 \mathrm{~h} / \mathrm{Co}^{2+}-2: 1\right)$ demonstrates the highest catalytic activity under $75{ }^{\circ} \mathrm{C}$ reaction temperature and $18 \mathrm{~h}$ reaction time $(58.30 \%$ conversion and $94.03 \%$ selectivity to allylic products). Furthermore, $\mathrm{HA} / \mathrm{HCl}-18 \mathrm{~h} / \mathrm{Co}^{2+}-2: 1$ has exhibit superior cycling stability with $37.69 \%$ conversion and $92.73 \%$ selectivity to allylic products after three cycles.
\end{abstract}

\section{Introduction}

Cyclohexene oxidation is an important reaction for the synthesis of oxygen-containing intermediates such as epoxy cyclohexane, 1,2-cyclohexanediol, adipic acid, 2-cyclohexen-1-one, 2cyclohexen-1-ol and cyclohexene peroxide, which widely applies in medicine, pesticides, spices, surfactant and polymer area. ${ }^{1}$ Among various oxidation products, allylic oxidation products (2cyclohexen-1-one and 2-cyclohexen-1-ol) arouse particularly attention because of their multifarious application in pharmaceutical, chemical and material industries..$^{2-4}$ However, due to the presence of multiple oxidation sites-unsaturated $\mathrm{C}=\mathrm{C}$ double bond and $\alpha-\mathrm{H}$ atoms, cyclohexene oxidation usually accompanies poor selectivity to allylic product, which will result in complex oxidation products and difficulty in separation. ${ }^{5}$ The commonly catalysts for the catalytic oxidation of cyclohexene to allylic product is supported metal based catalyst as they have the advantage of high stability, high catalytic activity and easy separation and recycling ${ }^{6-15}$ when compared with the homogeneous catalyst system. For various supports for metal based catalyst, mesoporous materials with tunable pore size, large specific

School of Chemical Science and Technology, Key Laboratory of Medicinal Chemistry for Natural Resource, Ministry of Education, Yunnan University, Kunming 650091, China. E-mail: licp830@iccas.ac.cn; Fax: +8687165031567

$\dagger$ Electronic supplementary information (ESI) available: Data of HA, eHA and eHA@ $\mathrm{Co}^{2+}$; effect of reaction condition on cyclohexene oxidation and recycling stability study with $\mathrm{HA} / \mathrm{HCl}-18 \mathrm{~h} / \mathrm{Co}^{2+}-R$ as catalyst. See DOI: $10.1039 / \mathrm{c} 7 \mathrm{ra} 11245 \mathrm{a}$ surface area and good stability are extensively investigated. ${ }^{\mathbf{1 2 - 1 5}}$ Through surface modification of the mesoporous material, and the active center coordination with the homogeneous catalyst, the mesoporous material supported catalyst is obtained and demonstrates good cyclohexene catalytic oxidation activity. For example, Khalili et al. support metal porphyrin (Mn(III)TClPPCl, Fe(III)TClPPCl and Co(III)TClPPCl) on MCM-48, and achieve 80\% cyclohexene conversion and 95\% selectivity to 2-cyclohexen-1-one with MCM-48 supported Fe(III)TClPPCl as catalyst and TBHP as oxidant in $\mathrm{CH}_{3} \mathrm{CN}$ at $60{ }^{\circ} \mathrm{C} .{ }^{12}$ Rahiman et al. demonstrate MCM41 supported metal porphyrins have various selectivity: the main oxidation product is epoxy cyclohexane when with MCM-41 supported manganoporphyrin as catalyst; whereas the main oxidation product is allylic products when with MCM-41 supported ferriporphyrin as catalyst. ${ }^{13}$ Park et al. prepare mesoporous silica with porphyrin structure by microwave cocondensation, and Fe(III) as the central atom is introduced into porphyrin by ion exchange. The mesoporous silica supported ferriporphyrin exhibits $41.5 \%$ cyclohexene conversion and $68.9 \%$ selectivity to allylic product at $60{ }^{\circ} \mathrm{C} .{ }^{14}$ However, to form uniform and ordered pore channels, soft template agent and high temperature calcinations are usually involved in, which result in complicated, time-consuming and energy consumption preparation process.

On the other hand, halloysite nanotube is a type of natural occurring clay minerals with nanotubular structures and consists of two-layered aluminosilicate with a chemical composition of $\left.\mathrm{Al}_{2} \mathrm{Si}_{2} \mathrm{O}_{5}(\mathrm{OH})_{4} \cdot n \mathrm{H}_{2} \mathrm{O}\right) .{ }^{16}$ Its structure and 
chemical composition is similar to that of kaolinite, dickite or nacrite except for the unit clay layers are separated by a monolayer of water molecules. ${ }^{17}$ Compared to other supports, halloysite nanotube has the advantage of abundant reserves, high porosity and excellent chemical stability, which is usually utilized as an attractive support for catalyst. ${ }^{18-27}$ In our previous studies, ${ }^{24}$ it has been demonstrated that mesoporous $\mathrm{SiO}_{2}$ and $\mathrm{SiO}_{2} / \mathrm{Al}_{2} \mathrm{O}_{3}$ can been controlled synthesized in large scale by selective etching of the interior $\mathrm{Al}_{2} \mathrm{O}_{3}$ from hydrophobically modified halloysite nanotube or halloysite nanotubes by $\mathrm{HCl}$. As the selective etching by $\mathrm{HCl}$ is the positive charged $\mathrm{Al}_{2} \mathrm{O}_{3}$, the surface of the etched halloysite nanotubes should be negative charged and can induce the adsorption of metal cation to achieve mesoporous etched halloysite nanotubes supported metal ions. Although mesoporous material supported metal cation has already been used in cyclohexene oxidation, mostly involves in supported metal compounds and complicated modification/treatment before supporting. And it is usually conducted with toxic, volatile solvent and expensive oxidant. ${ }^{12-15}$ For all we know, the influence of etching time, weight ratio of $\mathrm{Co}\left(\mathrm{NO}_{3}\right)_{2} \cdot 6 \mathrm{H}_{2} \mathrm{O}$ to etched $\mathrm{HA}(\mathrm{eHA})$ in the fabrication on the cyclohexene oxidation activity of mesoporous eHA supported $\mathrm{Co}^{2+}\left(\mathrm{eHA} @ \mathrm{Co}^{2+}\right)$, especially the environment-friendly cyclohexene oxidation process (solvent-free, $\mathrm{O}_{2}$ as oxidant and only bubbling with $\mathrm{O}_{2}$ a few minutes before oxidation reaction) and effective catalytic activity $(58.30 \%$ conversion and $94.03 \%$ selectivity to allylic products) have rarely been reported.

In this study, the mesoporous eHA supported $\mathrm{Co}^{2+}$ (eHA@ $\mathrm{Co}^{2+}$ ) are prepared through $\mathrm{HCl}$ selective etching and in situ $\mathrm{Co}^{2+}$ adsorption, consecutively. By simply tuning the etching time and feeding amount of $\mathrm{Co}^{2+}$ in the preparation, mesoporous eHA@ $\mathrm{Co}^{2+}$ with different BET specific surface area and $\mathrm{Co}^{2+}$ content can be achieved. The influence of catalyst (etching time, feeding amount of $\mathrm{Co}^{2+}$ and calcination in the preparation) and reaction condition (reaction time/temperature, solvent and oxidant) on the cyclohexene selective oxidation of mesoporous eHA@ $\mathrm{Co}^{2+}$ are investigated in detail. In addition, the cycling stability of eHA@ $\mathrm{Co}^{2+}$ is also investigated. In line with the results, a mechanism for cyclohexene oxidation is proposed.

\section{Experimental}

\subsection{Materials}

Halloysite nanotubes were purchased from Fenghui Minerals Trade Co., Ltd. Cobalt(II) nitrate hexahydrate $\left(\mathrm{Co}\left(\mathrm{NO}_{3}\right)_{2} \cdot 6 \mathrm{H}_{2} \mathrm{O}\right)$ and cyclohexene (99\%) were purchased from Shanghai Titan Scientific Co., Ltd. Hydrochloric acid ( $\mathrm{HCl})$, ethanol and trichloromethane $\left(\mathrm{CHCl}_{3}\right)$ were purchased from Chongqing Chuandong Chemical (Group) Co., Ltd. $\mathrm{O}_{2}$ (99.99\%) was purchased from Kunming Messer Gases Products Co., Ltd. All the chemical reagents were analytical grade and used directly.

\subsection{Selective etching of halloysite nanotubes}

In the preparation of mesoporous etched halloysite nanotube (eHA), the amounts of halloysite nanotubes and $36-38 \% \mathrm{HCl}$ were constant and the etching degree and morphology of eHA were regulated by the etching time. A typical procedure to prepare mesoporous eHA was as follows: ${ }^{24} \mathrm{HCl}$ solution (36$38 \%, 350 \mathrm{~mL}$ ) and halloysite nanotubes $(6.25 \mathrm{~g})$ were added into a $500 \mathrm{~mL}$ round flask. After dispersion with ultrasonication, the flask was placed in $80{ }^{\circ} \mathrm{C}$ oil bath, stirred and refluxed to selectively remove $\mathrm{Al}_{2} \mathrm{O}_{3}$. At certain etching time, some samples were withdrawn, washed repeatedly with water to neutral and dried at $75^{\circ} \mathrm{C}$. The eHA was marked as $\mathrm{HA} / \mathrm{HCl}-T$, wherein HA, $\mathrm{HCl}$ and $T$, respectively, represented halloysite nanotube, $\mathrm{HCl}$ as etching solution and etching time.

\subsection{The preparation of mesoporous etched halloysite nanotubes supported $\mathrm{Co}^{2+}$}

In the preparation of mesoporous eHA supported $\mathrm{Co}^{2+}$ $\left(\mathrm{eHA} @ \mathrm{Co}^{2+}\right)$, the above eHA without any modification was directly used as the support of $\mathrm{Co}^{2+}$ and the concentration of eHA was fixed. A typical process was as follows: eHA (0.50 g), $\mathrm{Co}\left(\mathrm{NO}_{3}\right)_{2} \cdot 6 \mathrm{H}_{2} \mathrm{O}(0.25-2.00 \mathrm{~g})$ and ethanol $(100 \mathrm{~mL})$ were added into a $150 \mathrm{~mL}$ conical flask. After dispersion with ultrasonication, the flask was stirred at room temperature for $24 \mathrm{~h}$. Then it was separated by centrifugation, washed with ethanol to colourless and dried at $75{ }^{\circ} \mathrm{C}$. This eHA supported $\mathrm{Co}^{2+}$ was marked as HA/ $\mathrm{HCl}-T / \mathrm{Co}^{2+}-R$, wherein $R$ represented the weight ratio of $\mathrm{Co}\left(\mathrm{NO}_{3}\right)_{2} \cdot 6 \mathrm{H}_{2} \mathrm{O}$ to eHA. Noting: the preparation process can be amplified; when compared with the amount of ethanol $(100 \mathrm{~mL})$, the amounts of eHA and $\mathrm{Co}\left(\mathrm{NO}_{3}\right)_{2} \cdot 6 \mathrm{H}_{2} \mathrm{O}$ were low for well dispersion of eHA and $\mathrm{Co}\left(\mathrm{NO}_{3}\right)_{2} \cdot 6 \mathrm{H}_{2} \mathrm{O}$ to achieve well dispersion of $\mathrm{Co}^{2+}$ in eHA; and the amount of $\mathrm{Co}\left(\mathrm{NO}_{3}\right)_{2} \cdot 6 \mathrm{H}_{2} \mathrm{O}$ was overdose in order to achieve adsorption saturation.

\subsection{Characterization}

The morphology of $\mathrm{HA} / \mathrm{HCl}-T$ and $\mathrm{HA} / \mathrm{HCl}-T / \mathrm{Co}^{2+}-R$ was characterized by JSM-2100 under an accelerating voltage of $200 \mathrm{kV}$. FT-IR was conducted on a Thermo Nicolet iS10 instrument with $\mathrm{KBr}$ pellet as background. The diffuse reflectance spectra of UVvis were performed on a Hitachi U-4100 PC photometer from 200 to $800 \mathrm{~nm}$. Energy-dispersive X-ray (EDX) analysis was performed with a FEI Quanta-200 scanning electron microscope (SEM) equipped with an EDX analyzer operated at an accelerating voltage of $10 \mathrm{kV}$. The quantification of the EDX analysis is based on the eZAF Smart Quant method calibrated with pure reference materials- $\mathrm{Cu}$ and $\mathrm{Al}$ sheet. Nitrogen adsorptiondesorption was performed on a Micromeritics (USA) Tristar II 3020. The oxidation product was detected by a gas chromatograph (Agilent 7890A). The gas chromatography was performed in a Agilent 19091J-413 column with a cross-linked 5\% phenyl methyl siloxan $(30 \mathrm{~m} \times 320 \mu \mathrm{m} \times 0.33 \mathrm{~mm})$ and a FID detector under the following conditions: $:^{27}$ carrier gas $\left(\mathrm{N}_{2}, 40 \mathrm{~mL} \mathrm{~min}^{-1}\right)$; temperature program $-40{ }^{\circ} \mathrm{C}$ holding for $2 \mathrm{~min}$, then heating to $50{ }^{\circ} \mathrm{C}$ at $10{ }^{\circ} \mathrm{C} \mathrm{min}^{-1}$, finally further heating to $300{ }^{\circ} \mathrm{C}$ at $50{ }^{\circ} \mathrm{C} \min ^{-1}$.

\subsection{Selective oxidation of cyclohexene by mesoporous etched halloysite nanotubes supported $\mathrm{Co}^{2+}$}

Catalyst $\left(\mathrm{HA} / \mathrm{HCl}-T / \mathrm{Co}^{2+}-R, 40 \mathrm{mg}\right)$ and cyclohexene $(0.8 \mathrm{~mL})$ were added to a $50 \mathrm{~mL}$ round-bottom flask. After bubbled with 
$\mathrm{O}_{2}$ for $10 \mathrm{~min}$ at appropriate flow rate to avoid the blown away of cyclohexene, the flask was placed in $75^{\circ} \mathrm{C}$ oil bath, stirred and refluxed (noting: the joint of the snake-shaped condenser and round-bottom flask must be carefully sealed by PTFE tape, parafilm " $\mathrm{M}$," and electric insulation tape consecutively to avoid the evaporation of cyclohexene). After $18 \mathrm{~h}$, it was separated by centrifugation, then $25 \mu$ l supernatant was withdraw and diluted with $1 \mathrm{~mL} \quad \mathrm{CHCl}_{3}$ for gas chromatograph characterization.

\section{Results and discussion}

\subsection{Characterization of mesoporous etched halloysite nanotubes supported $\mathrm{Co}^{2+}$}

The halloysite nanotube used for synthesis of mesoporous support for $\mathrm{Co}^{2+}$ is about 1-2 $\mu \mathrm{m}$ length, 20-30 $\mathrm{nm}$ inside diameter and 40-60 nm outside diameter (Fig. S1 in ESI $\dagger$ ). It consist of $17.5 \% \mathrm{Si}, 17.6 \% \mathrm{Al}$ and $64.9 \% \mathrm{O}$ and with $31.7 \mathrm{~m}^{2} \mathrm{~g}^{-1}$ BET surface area. ${ }^{\mathbf{1 9 2 0 , 2 2 - 2 7}}$ To demonstrate the $\mathrm{Al}_{2} \mathrm{O}_{3}$ in halloysite nanotubes can be controlled etched by $\mathrm{HCl}$, the TEM of etched halloysite nanotubes (eHA) at different etching time is given in Fig. 1. It shows when the etching time is $6 \mathrm{~h}$, the inside diameter of eHA increase from the original $20-30 \mathrm{~nm}$ to $45-55 \mathrm{~nm}$ and the interior surface is coarse. Furthermore, part of the tubular structure has been collapsed (Fig. 1a). This sample is labelled as $\mathrm{HA} / \mathrm{HCl}-6 \mathrm{~h}$. With increase the etching time, for example $7.5 \mathrm{~h}$ (HA/HCl-7.5 h) and $11 \mathrm{~h}(\mathrm{HA} / \mathrm{HCl}-11 \mathrm{~h})$, nearly all of the interior surface is left exposed accompanied by the disappearance of the inner cavity (Fig. 1b and c). When the etching time is $18 \mathrm{~h}$, porous nanorods with totally lost of the tubular structure are achieved (HA/HCl-18 h) (Fig. 1d). Based on the TEM results, the process for selective etching of $\mathrm{Al}_{2} \mathrm{O}_{3}$ from $\mathrm{HA}$ can be explained as follows: firstly, nanotubes with varying enlargement of the cavity are achieved when a handful of $\mathrm{Al}_{2} \mathrm{O}_{3}$ is removed; secondly, pores in the HA walls begin to appear and grow with the etching time when more $\mathrm{Al}_{2} \mathrm{O}_{3}$ is removed; finally, tubular
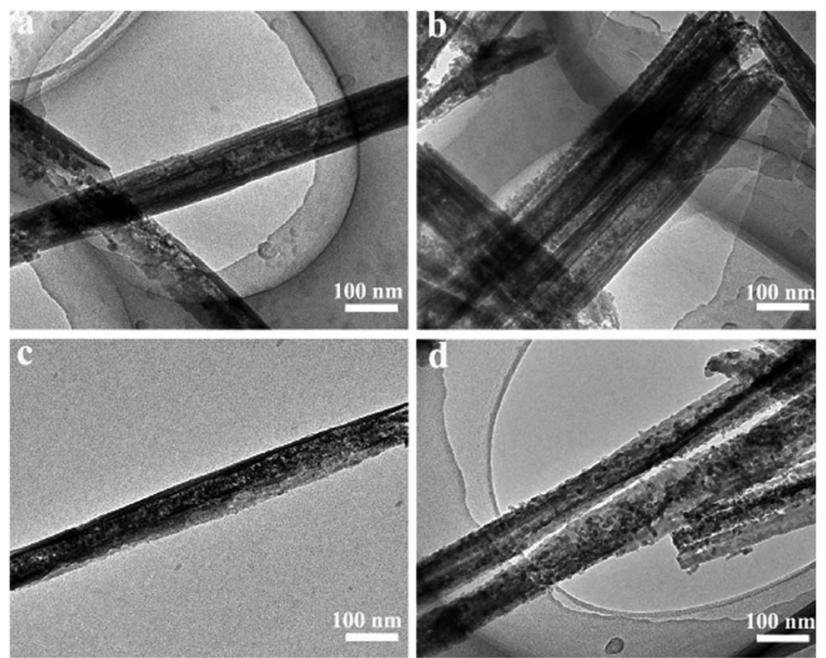

Fig. 1 TEM images of halloysite nanotubes after being etched by $\mathrm{HCl}$ at $80^{\circ} \mathrm{C}$ for (a) $6 \mathrm{~h}$, (b) $7.5 \mathrm{~h}$, (c) $11 \mathrm{~h}$ and (d) $18 \mathrm{~h}$, respectively. morphology is lost and cavity disappears when the $\mathrm{Al}_{2} \mathrm{O}_{3}$ is completely removed..$^{\mathbf{2 4 , 2 8}}$

FT-IR is further used to characterize the eHA. Along increasing the etching time, the bands intensity of the $\mathrm{Al}_{2} \mathrm{OH}$ stretching (3696 and $3620 \mathrm{~cm}^{-1}$ ) and the single $\mathrm{Al}_{2} \mathrm{OH}$ bending (912 $\mathrm{cm}^{-1}$ ) gradually decrease (Fig. 2). ${ }^{\mathbf{1 6 2 4 , 2 8}}$ In addition, the bands intensity of $\mathrm{Si}-\mathrm{O}-\mathrm{Al}$ in plane bending mode $\left(754,692\right.$ and $\left.534 \mathrm{~cm}^{-1}\right)$ also show the same trend with the increase of etching time (along further etching). Correspondingly, SiO-H vibrations band at $3200-3700 \mathrm{~cm}^{-1}$ appears (the formation of silica) and the band intensity of symmetric $\mathrm{Si}-\mathrm{O}-\mathrm{Si}$ stretching $\left(798 \mathrm{~cm}^{-1}\right)$ increases with the etching time. The above result demonstrates the removal of $\mathrm{Al}_{2} \mathrm{O}_{3}$ can be controlled. ${ }^{24,28,29}$ Eventually, all the $\mathrm{Al}_{2} \mathrm{O}_{3}$ characteristic bands disappear (trace e, Fig. 2). The Si-O stretching band of halloysite nanotubes $\left(1032 \mathrm{~cm}^{-1}\right)$ completely disappears accompanied by the enhance of the in-plane $\mathrm{Si}-\mathrm{O}-\mathrm{Si}$ deformation peak $\left(1092 \mathrm{~cm}^{-1}\right)$ and the final spectra bear a resemblance to that of amorphous $\mathrm{SiO}_{2} \cdot{ }^{30}$ The eHA is further characterized by XRD and EDX. It demonstrates the single 1:1 layer aluminosilicate thickness $(7.30 \AA)$, other typical reflections of halloysite $(4.41 \AA$, $3.61 \AA, 2.49 \AA$, $2.36 \AA$, $2.22 \AA, 1.68 \AA, 1.48 \AA$ ) (Fig. S2 in ESI $\dagger$ ) and $\mathrm{Al} / \mathrm{Si}$ atom ratio (Table $\mathrm{S} 1$ in $\mathrm{ESI} \dagger$ ) decrease with etching time, and eventually disappear with a broad band peak present which is attributed to amorphous $\mathrm{SiO}_{2}$ for XRD and to nearly zero for $\mathrm{Al} / \mathrm{Si}$ atom ratio, respectively. The above results are consistent with the result of $\mathrm{HCl}$ selective etching of octadecyltrichlorosilane silane (C18) modified halloysite nanotube. ${ }^{24}$

The mesoporous structure of eHA is characterized by nitrogen adsorption-desorption. It exhibits clearly halloysite nanotube itself is a mesoporous material (Fig. 3). In addition, according to the International Union of Pure and Applied Chemistry (IUPAC) classification (Fig. 3, Table S2 in ESI $\dagger$ ), the adsorption-desorption isotherm of halloysite nanotubes is ascribed to type IV with H3 hysteresis loops as majority of the pore diameter were in the range of $2-8 \mathrm{~nm}$ and $15-35 \mathrm{~nm} .{ }^{31}$ The average pore diameter, pore volume and BET surface area of

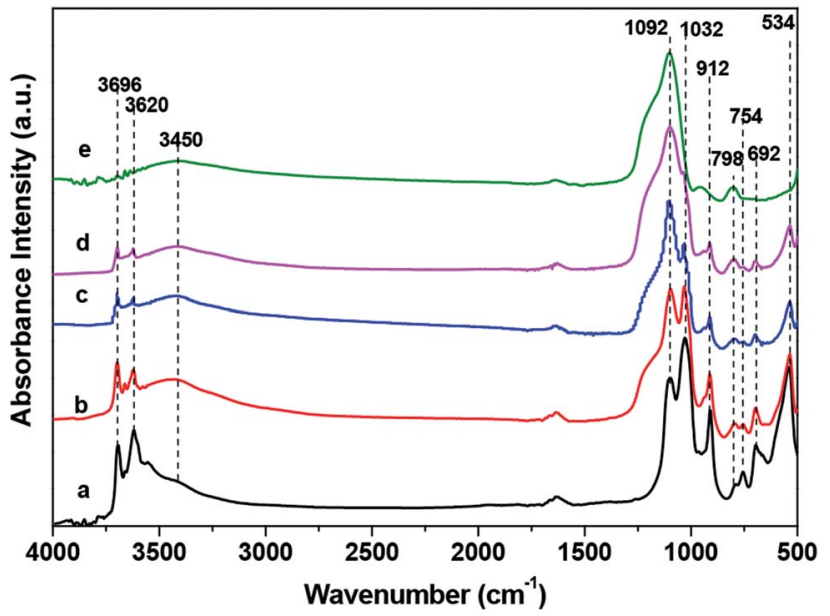

Fig. 2 FT-IR of halloysite nanotubes (a) and halloysite nanotubes after being etched by $\mathrm{HCl}$ at $80^{\circ} \mathrm{C}$ for (b) $6 \mathrm{~h}$, (c) $7.5 \mathrm{~h}$, (d) $11 \mathrm{~h}$ and (e) $18 \mathrm{~h}$, respectively. 
A
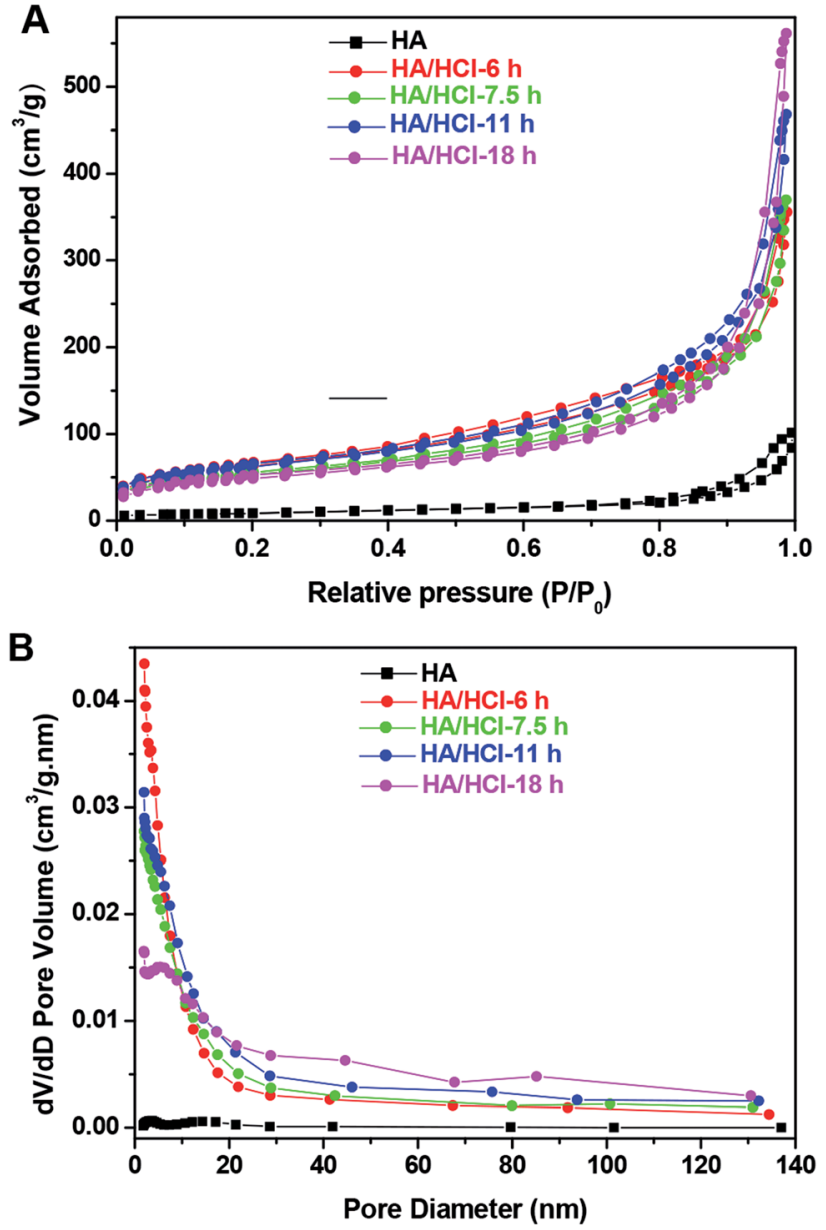

Fig. 3 Nitrogen adsorption-desorption isotherms (A) and pore size distribution curves $(B)$ of halloysite $(\mathrm{HA})$ and $\mathrm{HA} / \mathrm{HCl}-T$.

halloysite nanotubes are respectively $11.5 \mathrm{~nm}, 0.16 \mathrm{~cm}^{3} \mathrm{~g}^{-1}$ and $31.7 \mathrm{~cm}^{2} \mathrm{~g}^{-1}$. Compared with those of halloysite nanotubes, the pore volume of eHA is higher and the pore diameter is lower (Fig. 3B, Table S2 in ESI $\dagger$ ) when the etching time is lower than $18 \mathrm{~h}$ and an opposite situation is observed when the etching time is $18 \mathrm{~h}$ (Fig. 3B, Table S2 in ESI $\dagger$ ). After selective etching, mesopores in the sizes of $3.0 \mathrm{~nm}$ observed in the parent halloysite nanotubes has shifted to larger size, especially for the $\mathrm{HA} / \mathrm{HCl}-18 \mathrm{~h}$ sample (has shifted to $5.4 \mathrm{~nm}$ ), while the pores about $14 \mathrm{~nm}$ has shifted to higher position or has disappeared. This indicates that the cavity in the eHA has been partly destroyed or completely disappeared, which is in good agreement with the results of the TEM images. What is deserved to mention that the BET surface area is increased evidently from $31.7 \mathrm{~m}^{2} \mathrm{~g}^{-1}$ for the halloysite nanotube to $176.5 \mathrm{~m}^{2} \mathrm{~g}^{-1}$ for the HA/HCl-6 h sample. However, with further increasing the etching time, the increase of BET surface area is not significant, for example, with the etching time increase from $6 \mathrm{~h}$ to $18 \mathrm{~h}$, the BET surface area just increases to $228.4 \mathrm{~m}^{2} \mathrm{~g}^{-1}$ from $176.5 \mathrm{~m}^{2}$ $\mathrm{g}^{-1}$ (Table S2 in ESI $\dagger$ ). The raise of the BET surface area of eHA could be resulted from the selective etching of $\mathrm{Al}_{2} \mathrm{O}_{3}$ from halloysite nanotubes, which will increase surface roughness and porosity (Fig. 3). It also can be seen with the increase of etching time, the average pore diameter and pore volume of the eHA also increase, implying they can be conditioned by the etching time. As an example, with the increase of etching time from $6 \mathrm{~h}$ to $18 \mathrm{~h}$, the average pore diameter and pore volume, respectively, increase from $6.8 \mathrm{~nm}$ to $12.0 \mathrm{~nm}$ and $0.56 \mathrm{~cm}^{3} \mathrm{~g}^{-1}$ to 0.87 $\mathrm{cm}^{3} \mathrm{~g}^{-1}$.

The above mesoporous eHA is used to support $\mathrm{Co}^{2+}$ by an impregnation method and marked as $\mathrm{HA} / \mathrm{HCl}-T / \mathrm{Co}^{2+}-R$, wherein $R$ represent the weight ratio of $\mathrm{Co}\left(\mathrm{NO}_{3}\right)_{2} \cdot 6 \mathrm{H}_{2} \mathrm{O}$ to eHA. Fig. 4 shows the TEM of $\mathrm{HA} / \mathrm{HCl}-18 \mathrm{~h}$ after immerging in different concentration of $\mathrm{Co}\left(\mathrm{NO}_{3}\right)_{2} \cdot 6 \mathrm{H}_{2} \mathrm{O}$ solution. It is demonstrable that the rough/porous structure of $\mathrm{HA} / \mathrm{HCl}-18 \mathrm{~h}$ is not affected. Moreover, there are $2.5 \mathrm{~nm}$ black spots on eHA and the amount increases with the increase of weight ratio of $\mathrm{Co}\left(\mathrm{NO}_{3}\right)_{2} \cdot 6 \mathrm{H}_{2} \mathrm{O}$ to $\mathrm{HA} / \mathrm{HCl}-18 \mathrm{~h}$ (Fig. 4, Table S3 in ESI $\dagger$ ). We ascribe them to the $\mathrm{Co}^{2+}$ ionic clusters. The Co content of the $\mathrm{HA} / \mathrm{HCl}-18 \mathrm{~h} / \mathrm{Co}^{2+}-\mathrm{R}$ is roughly determined by EDX. The FT-IR of eHA@ $\mathrm{Co}^{2+}$ has no significant difference from that of eHA (Fig. S3 in ESI $\dagger$ ). The above results indicate $\mathrm{Co}^{2+}$ can be supported on the eHA by the impregnation method and the supported amount of $\mathrm{Co}^{2+}$ can be tuned by the feeding amount of weight ratio of $\mathrm{Co}\left(\mathrm{NO}_{3}\right)_{2} \cdot 6 \mathrm{H}_{2} \mathrm{O}$ to $\mathrm{HA} / \mathrm{HCl}-18 \mathrm{~h}$ in the preparation. It's hard to ignore that the $\mathrm{Al} / \mathrm{Si}$ atom ratio and Co content (wt\%) determined by EDX are not accurate as there are many factors affecting the EDX test result, for example the flatness/ concentrations of sample, the distribution of elements, accelerating voltage of SEM and so on. However, EDX can be used to present the change trend of the $\mathrm{Al} / \mathrm{Si}$ atom ratio and Co content with the increase of etching time and the weight ratio of $\mathrm{Co}\left(\mathrm{NO}_{3}\right)_{2} \cdot 6 \mathrm{H}_{2} \mathrm{O}$ to eHA, respectively.

\subsection{Solvent-free oxidation of cyclohexene to allylic products with oxygen by mesoporous eHA@ $\mathrm{Co}^{2+}$}

Mesoporous eHA@Co ${ }^{2+}\left(\mathrm{HA} / \mathrm{HCl}-T / \mathrm{Co}^{2+}-R\right)$ is directly used as catalyst for cyclohexene oxidation at $75{ }^{\circ} \mathrm{C}$ with $\mathrm{O}_{2}$ as oxidant
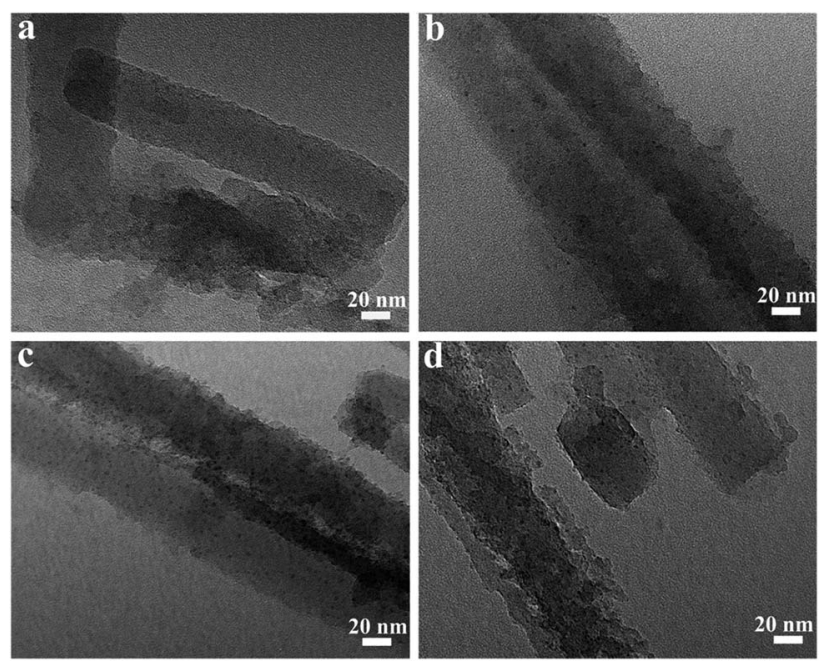

Fig. 4 TEM images of eHACCo ${ }^{2+}$ : (a) $\mathrm{HA} / \mathrm{HCl}-18 \mathrm{~h} / \mathrm{Co}^{2+}-0.5: 1$, (b) $\mathrm{HA} / \mathrm{HCl}-18 \mathrm{~h} / \mathrm{Co}^{2+}-1: 1$, (c) $\mathrm{HA} / \mathrm{HCl}-18 \mathrm{~h} / \mathrm{Co}^{2+}-2: 1$ and (d) $\mathrm{HA} / \mathrm{HCl}-$ $18 \mathrm{~h} / \mathrm{Co}^{2+}-4: 1$. 
(noting: the reaction system is only bubbled with $\mathrm{O}_{2}$ for $10 \mathrm{~min}$ before reaction; during the reaction, no $\mathrm{O}_{2}$ is bubbled or $\mathrm{O}_{2}$ balloon is added). And for facilitating comparison, the cyclohexene oxidation efficiency of $\mathrm{HA}, \mathrm{HA} / \mathrm{HCl}-18 \mathrm{~h}$ (etched with $\mathrm{HCl}$ for $18 \mathrm{~h}$, but without supporting $\mathrm{Co}^{2+}$ ), $\mathrm{HA} / \mathrm{Co}^{2+}-2: 1$ (HA directly supporting $\mathrm{Co}^{2+}$ at $2: 1$ weight ratio of $\mathrm{Co}\left(\mathrm{NO}_{3}\right)_{2} \cdot 6 \mathrm{H}_{2} \mathrm{O}$ to $\left.\mathrm{HA}\right)$ and bulk $\mathrm{Co}\left(\mathrm{NO}_{3}\right)_{2} \cdot 6 \mathrm{H}_{2} \mathrm{O}$ are also studied. It is demonstrable that cyclohexene oxidation with $\mathrm{HA}, \mathrm{HA} / \mathrm{HCl}-18 \mathrm{~h}$ and $\mathrm{HA} / \mathrm{Co}^{2+}-2: 1$ as catalyst and catalyst-free demonstrates extremely low cyclohexene conversion $(1.63 \%, 9.30 \%, 9.58 \%$ and $8.13 \%$, respectively). Nevertheless with $\mathrm{HA} / \mathrm{HCl}-T / \mathrm{Co}^{2+}-R$ as catalyst, cyclohexene conversion increase significantly, for example, with $\mathrm{HA} / \mathrm{HCl}-18 \mathrm{~h} / \mathrm{Co}^{2+}-2: 1$ as catalyst, the cyclohexene conversion increases to $58.30 \%$. In combination of $9.58 \%$ and $9.30 \%$ cyclohexene conversion with $\mathrm{HA} / \mathrm{Co}^{2+}-2: 1$ and $\mathrm{HA} / \mathrm{HCl}-18 \mathrm{~h}$ as catalyst, respectively, the above results signify both of the porous structure of eHA and supported $\mathrm{Co}^{2+}$ are contributed to the enhanced cyclohexene oxidation activity of $\mathrm{HA} / \mathrm{HCl}-T / \mathrm{Co}^{2+}-R$. However, the cyclohexene oxidation efficiency of $\mathrm{HA} / \mathrm{HCl}-T / \mathrm{Co}^{2+}$ $R$ is varied along the change of etching time $(T)$ and weight ratio of $\mathrm{Co}\left(\mathrm{NO}_{3}\right)_{2} \cdot 6 \mathrm{H}_{2} \mathrm{O}$ to eHA $(R)$ in the preparation. For the influence of etching time, at $2: 1$ weight ratio of $\mathrm{Co}\left(\mathrm{NO}_{3}\right)_{2} \cdot 6 \mathrm{H}_{2} \mathrm{O}$ to eHA, cyclohexene conversion increase with the etching time. For example, when the etching time increases from $0 \mathrm{~h}$ to $18 \mathrm{~h}$, the cyclohexene conversion increases from $9.58 \%$ to $58.30 \%$ and an optimal etching time is $18 \mathrm{~h}$ (Entry 2-6, Table 1 ). The tendency is consistent with the BET surface area of eHA (longer etching time will result in higher BET surface area, which finally lead to higher $\mathrm{Co}^{2+}$ supporting content). Evidently, the etching time in the preparation will affect the cyclohexene oxidation efficiency of $\mathrm{HA} /$ $\mathrm{HCl}-T / \mathrm{Co}^{2+}-R$.

For the effect of weight ratio of $\mathrm{Co}\left(\mathrm{NO}_{3}\right)_{2} \cdot 6 \mathrm{H}_{2} \mathrm{O}$ to eHA in the preparation, when the weight ratio of $\mathrm{Co}\left(\mathrm{NO}_{3}\right)_{2} \cdot 6 \mathrm{H}_{2} \mathrm{O}$ to eHA is between $0.5: 1-2: 1$ (Table 1, Fig. S4 in ESI $\dagger$ ), cyclohexene conversion increases with the increase of $\mathrm{Co}\left(\mathrm{NO}_{3}\right)_{2} \cdot 6 \mathrm{H}_{2} \mathrm{O} / \mathrm{eHA}$ weight ratio, and then when the $\mathrm{Co}\left(\mathrm{NO}_{3}\right)_{2} \cdot 6 \mathrm{H}_{2} \mathrm{O} / \mathrm{eHA}$ weight ratio is in the range of $2: 1-4: 1$, the cyclohexene conversion decreases with the increase of $\mathrm{Co}\left(\mathrm{NO}_{3}\right)_{2} \cdot 6 \mathrm{H}_{2} \mathrm{O} / \mathrm{eHA}$ weight ratio. An optimal $\mathrm{Co}\left(\mathrm{NO}_{3}\right)_{2} \cdot 6 \mathrm{H}_{2} \mathrm{O} / \mathrm{eHA}$ weight ratio in the fabrication is $2: 1$. The effect of $\mathrm{Co}\left(\mathrm{NO}_{3}\right)_{2} \cdot 6 \mathrm{H}_{2} \mathrm{O} / \mathrm{eHA}$ weight ratio on the conversion is attributed to a cooperative effect of Co content and $\mathrm{Co}^{2+}$ dispersion on the eHA. Combined with the EDX result that the Co content increases with the increase of $\mathrm{Co}\left(\mathrm{NO}_{3}\right)_{2} \cdot 6 \mathrm{H}_{2} \mathrm{O} / \mathrm{eHA}$ weight ratio (Table $\mathrm{S} 3$ in ESI $\dagger$ ), the cyclohexene oxidation efficiency of $\mathrm{HA} / \mathrm{HCl}-T / \mathrm{Co}^{2+}-R$ will be affected by the Co content in the mesoporous eHA@ $\mathrm{Co}^{2+}\left(\mathrm{Co}\left(\mathrm{NO}_{3}\right)_{2}\right.$ $\cdot 6 \mathrm{H}_{2} \mathrm{O} / \mathrm{eHA}$ weight ratio in the preparation). It is deserved to mention that the cyclohexene conversion, TON and $r_{\mathrm{w}}$ of HA/ HCl-18 h/Co ${ }^{2+}-2: 1$ are higher than those of the bulk $\mathrm{Co}\left(\mathrm{NO}_{3}\right)_{2} \cdot 6 \mathrm{H}_{2} \mathrm{O}$ (Entry 6, 14, Table 1 ) at the equivalent amount of $\mathrm{Co}$, indicating the porous structure of $\mathrm{HA} / \mathrm{HCl}-18 \mathrm{~h}$ can well disperse $\mathrm{Co}^{2+}$. About the selectivity, the main oxidation products are allylic products (2-cyclohexen-1-one and 2-cyclohexen1-ol) and the selectivity to allylic products accounts for more than $90 \%$.

Furthermore, as the chemical composition of $\mathrm{HA}$ is $\mathrm{Al}_{2} \mathrm{Si}_{2}$ $\left.\mathrm{O}_{5}(\mathrm{OH})_{4} \cdot n \mathrm{H}_{2} \mathrm{O}\right)$, the $\mathrm{SiO}_{2}$ in $\mathrm{HA}$ can be selectively etched by
$\mathrm{NaOH}$. The sample etched by $\mathrm{NaOH}$ for $18 \mathrm{~h}(\mathrm{HA} / \mathrm{NaOH}-18 \mathrm{~h})$ is used to support $\mathrm{Co}^{2+}$ with $1: 1,2: 1$ and $4: 1$ weight ratio of $\mathrm{Co}\left(\mathrm{NO}_{3}\right)_{2} \cdot 6 \mathrm{H}_{2} \mathrm{O}$ to $\mathrm{HA} / \mathrm{NaOH}-18 \mathrm{~h}$. It still shows the optimal weight ratio is $2: 1$, which achieves $29.06 \%$ cyclohexene conversion. For the oxidation product of $\mathrm{HA} / \mathrm{NaOH}-18 \mathrm{~h} / \mathrm{Co}^{2+}-R$, it is still allylic product (the selectivity is higher than $79 \%$ ). However, the catalytic activity of $\mathrm{HA} / \mathrm{NaOH}-18 \mathrm{~h} / \mathrm{Co}^{2+}-R$ is lower than that of $\mathrm{HA} / \mathrm{HCl}-18 \mathrm{~h} / \mathrm{Co}^{2+}-R$ at the same weight ratio of $\mathrm{Co}\left(\mathrm{NO}_{3}\right)_{2} \cdot 6 \mathrm{H}_{2} \mathrm{O}$ to eHA, indicating $\mathrm{HA} / \mathrm{HCl}-T$ can support more $\mathrm{Co}^{2+}$ owing to the negative charged of $\mathrm{SiO}_{2}$ in $\mathrm{HA} / \mathrm{HCl}-T$.

Notably, the selectivity to allylic product of cyclohexene oxidation catalyzed by $\mathrm{HA} / \mathrm{HCl}-T / \mathrm{Co}^{2+}-R$ exceeds $90 \%$, independence on the etching time and $\mathrm{Co}\left(\mathrm{NO}_{3}\right)_{2} \cdot 6 \mathrm{H}_{2} \mathrm{O} / \mathrm{eHA}$ weight ratio in the preparation, which will simplify the later purification and separation. The cyclohexene conversion and selectivity to allylic products (2-cyclohexen-1-one and 2-cyclohexen-1-ol) with $\mathrm{HA} / \mathrm{HCl}-18 \mathrm{~h} / \mathrm{Co}^{2+}-2: 1$ as catalyst are $58.30 \%$ and 94.03\% respectively, indicating it can selectively oxidize cyclohexene to allylic products. Both of the cyclohexene conversion and selectivity to allylic products are higher than that of $\mathrm{Co}(\mathrm{II})$ containing MOFs (Co-MOF, 32.80\% conversion and 90.80\% selectivity to allylic products), even both the reaction temperature $\left(75{ }^{\circ} \mathrm{C}\right)$ and time $(18 \mathrm{~h})$ are lower than that of $\mathrm{Co}(\mathrm{II})$-containing MOFs $\left(80{ }^{\circ} \mathrm{C}\right.$ and $\left.20 \mathrm{~h}\right)$ and the simplification of oxidation process (only bubbled with $\mathrm{O}_{2}$ for $10 \mathrm{~min}$ before reaction; during the reaction, no $\mathrm{O}_{2}$ is bubbled or $\mathrm{O}_{2}$ balloon is added). ${ }^{6}$ Based on the above results, the etching time and $\mathrm{Co}\left(\mathrm{NO}_{3}\right)_{2} \cdot 6 \mathrm{H}_{2} \mathrm{O} / \mathrm{eHA}$ weight ratio in the preparation will exert a significant impact on the cyclohexene oxidation efficiency of $\mathrm{HA} / \mathrm{HCl}-T / \mathrm{Co}^{2+}-R$. Thereinto, $\mathrm{HA} / \mathrm{HCl}-18 \mathrm{~h} / \mathrm{Co}^{2+}-2: 1$ performs the highest catalytic efficiency, corresponding to a 1209.98 TON and $1140.69 \mathrm{mmol} \mathrm{g}^{-1} \mathrm{~h}^{-1}$ mass-normalized activity. This activity is significantly higher than that of halloysite nanotubes supported PANI (PANI@HA/1 M/2.04-HCl, 148.66 TON and $\left.67.33 \mathrm{mmol} \mathrm{g}^{-1} \mathrm{~h}^{-1}\right)^{27}$ and Co(II)-containing metal-organic frameworks (MOFs) (Co-MOF, 80.22 TON and $68.07 \mathrm{mmol} \mathrm{g}^{-1}$ $\left.\mathrm{h}^{-1}\right) .{ }^{6}$ So $\mathrm{HA} / \mathrm{HCl}-18 \mathrm{~h} / \mathrm{Co}^{2+}-2: 1$ is an effective catalyst for allylic oxidation of cyclohexene and chosen for further studies.

Furthermore, the effect of calcinations on the cyclohexene catalytic oxidation activity of $\mathrm{HA} / \mathrm{HCl}-18 \mathrm{~h} / \mathrm{Co}^{2+}{ }_{-2}: 1$ and $\mathrm{HA} /$ $\mathrm{NaOH}-18 \mathrm{~h} / \mathrm{Co}^{2+}-2: 1$ is investigated. HA/HCl-18 $\mathrm{h} / \mathrm{Co}^{2+}-2: 1$ and $\mathrm{HA} / \mathrm{NaOH}-18 \mathrm{~h} / \mathrm{Co}^{2+}-2: 1$ are treated at $550{ }^{\circ} \mathrm{C}$ for $6 \mathrm{~h}$, cited as $\mathrm{HA} / \mathrm{HCl}-18 \mathrm{~h} / \mathrm{Co}^{2+}-2: 1 / 550{ }^{\circ} \mathrm{C}-6 \mathrm{~h}$ and $\mathrm{HA} / \mathrm{NaOH}-18 \mathrm{~h} / \mathrm{Co}^{2+}$ 2 : $1 / 550{ }^{\circ} \mathrm{C}-6 \mathrm{~h}$, respectively (Entry 2 and 4, Table S4 in ESI $\dagger$ ). And they are used as catalyst and compared with those without calcinations (Entry 1 and 3, Table S4 in ESI $\dagger$ ). It is demonstrable calcinations will decrease the catalytic activity of $\mathrm{HA} / \mathrm{HCl}-18 \mathrm{~h} /$ $\mathrm{Co}^{2+}-2: 1$, whereas it has a positive effect on $\mathrm{HA} / \mathrm{NaOH}-18 \mathrm{~h} /$ $\mathrm{Co}^{2+}-2: 1$. It can be explained by the fact calcinations will lead to the aggregation of $\mathrm{Co}^{2+}$ or cobalt oxide for $\mathrm{HA} / \mathrm{HCl}-18 \mathrm{~h} / \mathrm{Co}^{2+}$ $2: 1$ owing to the adsorption saturation of $\mathrm{Co}^{2+}$ on $\mathrm{HA} / \mathrm{HCl}-18 \mathrm{~h} /$ $\mathrm{Co}^{2+}-2: 1$, whereas it will solid the adsorbed $\mathrm{Co}^{2+}$ on $\mathrm{HA} / \mathrm{NaOH}-$ $18 \mathrm{~h} / \mathrm{Co}^{2+}-2$ : 1 because $\mathrm{NaOH}$ etching will lead to partly positive charged $\mathrm{Al}_{2} \mathrm{O}_{3}$, which will produce electrostatic repulsion to $\mathrm{Co}^{2+}$. Therefore, $\mathrm{HA} / \mathrm{HCl}-18 \mathrm{~h} / \mathrm{Co}^{2+}-2: 1$ is selected for optimization of reaction condition. 
Table 1 Cyclohexene conversion and selectivity of $\mathrm{HA} / \mathrm{HCl}-\mathrm{T} / \mathrm{CO}^{2+}-R$ and $\mathrm{HA} / \mathrm{NaOH}-\mathrm{T} / \mathrm{Co}^{2+}-R$

\begin{tabular}{|c|c|c|c|c|c|c|c|}
\hline \multirow[b]{2}{*}{ Catalyst } & \multicolumn{4}{|c|}{ Selectivity (\%) } & \multirow[b]{2}{*}{ Conversion $(\%)$} & \multirow[b]{2}{*}{$\operatorname{TON}^{a}$} & \multirow[b]{2}{*}{$r_{\mathrm{w}}^{b}\left(\mathrm{mmol} \mathrm{g}{ }^{-1} \mathrm{~h}\right)$} \\
\hline & & & & & & & \\
\hline HA & 0 & 5.52 & 59.74 & 34.74 & 1.63 & - & - \\
\hline $\mathrm{HA} / \mathrm{Co}^{2+}-2: 1$ & 0 & 10.76 & 45.86 & 43.38 & 9.58 & - & - \\
\hline $\mathrm{HA} / \mathrm{HCl}-6 \mathrm{~h} / \mathrm{Co}^{2+}-2: 1$ & 0 & 5.10 & 69.02 & 25.88 & 10.49 & - & - \\
\hline $\mathrm{HA} / \mathrm{HCl}-7.5 \mathrm{~h} / \mathrm{Co}^{2+}-2: 1$ & 0 & 8.97 & 53.36 & 37.66 & 16.82 & - & - \\
\hline $\mathrm{HA} / \mathrm{HCl}-11 \mathrm{~h} / \mathrm{Co}^{2+}-2: 1$ & 0.45 & 5.14 & 65.57 & 28.84 & 23.92 & - & - \\
\hline $\mathrm{HA} / \mathrm{HCl}-18 \mathrm{~h} / \mathrm{Co}^{2+}-2: 1$ & 0.27 & 5.70 & 54.60 & 39.43 & 58.30 & 1209.98 & 1140.69 \\
\hline HA/HCl-18 h & 1.51 & 0 & 59.17 & 39.31 & 9.30 & - & - \\
\hline $\mathrm{HA} / \mathrm{HCl}-18 \mathrm{~h} / \mathrm{Co}^{2+}-0.5: 1$ & 3.34 & 1.10 & 51.73 & 43.83 & 18.33 & 1065.20 & 1004.20 \\
\hline $\mathrm{HA} / \mathrm{HCl}-18 \mathrm{~h} / \mathrm{Co}^{2+}-1: 1$ & 3.50 & 4.88 & 49.16 & 42.46 & 26.63 & 644.80 & 607.88 \\
\hline $\mathrm{HA} / \mathrm{HCl}-18 \mathrm{~h} / \mathrm{Co}^{2+}-4: 1$ & 1.09 & 4.70 & 60.68 & 33.53 & 29.27 & 507.74 & 478.67 \\
\hline $\mathrm{HA} / \mathrm{NaOH}-18 \mathrm{~h} / \mathrm{Co}^{2+}-1: 1$ & 1.10 & 8.76 & 49.22 & 40.93 & 19.21 & - & - \\
\hline $\mathrm{HA} / \mathrm{NaOH}-18 \mathrm{~h} / \mathrm{Co}^{2+}-2: 1$ & 2.05 & 17.95 & 54.22 & 25.77 & 29.06 & - & - \\
\hline $\mathrm{HA} / \mathrm{NaOH}-18 \mathrm{~h} / \mathrm{Co}^{2+}-4: 1$ & 0.82 & 7.48 & 60.02 & 31.68 & 22.51 & - & - \\
\hline $\mathrm{Co}\left(\mathrm{NO}_{3}\right)_{2} \cdot 6 \mathrm{H}_{2} \mathrm{O}^{c}$ & 5.40 & 3.52 & 60.87 & 30.20 & 13.59 & 282.05 & 265.90 \\
\hline Catalyst-free & 5.20 & 50.34 & 14.68 & 29.78 & 8.13 & - & - \\
\hline $\begin{array}{l}\text { Halloysite nanotubes supported } \\
\text { PANI (PANI@HA } / 1 \mathrm{M} / 2.04-\mathrm{HCl})^{d}\end{array}$ & 0 & 99.50 & 0.05 & 0.45 & 98.17 & 148.66 & 67.33 \\
\hline Co(II)-containing & 3.05 & 0 & 51.26 & 39.34 & 32.80 & 80.22 & 68.07 \\
\hline
\end{tabular}

metal-organic frameworks ${ }^{e}$

Reaction conditions: $40 \mathrm{mg}$ catalyst, $0.8 \mathrm{~mL}$ cyclohexene, $\mathrm{O}_{2}(10 \mathrm{~min}), 75^{\circ} \mathrm{C}, 18 \mathrm{~h} .{ }^{a}$ TON (turnover number) is defined as total mol of cyclohexene molecules converted per mol of catalyst. ${ }^{b}$ Initial reaction rate of cyclohexene consumption normalized by catalyst mass. ${ }^{c}$ The added amount of $\mathrm{Co}\left(\mathrm{NO}_{3}\right)_{2} \cdot 6 \mathrm{H}_{2} \mathrm{O}$ is $1.1 \mathrm{mg}$, comparable to the amount of Co in $40 \mathrm{mg} \mathrm{HA} / \mathrm{HCl}-18 \mathrm{~h} / \mathrm{Co}^{2+}-2: 1{ }^{d}$ Reaction conditions: $20 \mathrm{mg}$ catalyst, $1.23 \mathrm{~mL}$ cyclohexene, $2.5 \mathrm{~mL} \mathrm{H}_{2} \mathrm{O}_{2}, 70{ }^{\circ} \mathrm{C}, 24 \mathrm{~h}$ (ref. 27 ). ${ }^{e}$ Reaction conditions: $50 \mathrm{mg}$ catalyst, $5 \mathrm{~mL}$ cyclohexene, oxygen balloon, $80{ }^{\circ} \mathrm{C}, 20 \mathrm{~h}$ (ref. 6 ).

In the next, optimization of reaction condition (such as oxidant, solvent, reaction time and reaction temperature) for cyclohexene oxidation by $\mathrm{HA} / \mathrm{HCl}-18 \mathrm{~h} / \mathrm{Co}^{2+}-2: 1$ is further undergoing. At first, the effect of oxidant on cyclohexene oxidation is investigated. Considering environmentally-friendly aspect, $\mathrm{O}_{2}$ and $30 \% \mathrm{H}_{2} \mathrm{O}_{2}$ are chosen as oxidant. The detailed result is shown on Table S5. $\dagger$ It is clearly when bubbling $\mathrm{O}_{2}$ for $10 \mathrm{~min}$ before oxidation, cyclohexene conversion achieves $58.30 \%$; whereas without bubbling $\mathrm{O}_{2}$, the conversion is only $10.41 \%$. Combined with $10.41 \%$ cyclohexene conversion of HA/ HCl-18 h/Co ${ }^{2+}-2: 1$ without bubbling $\mathrm{O}_{2}$ (Entry 2, Table S5 in ESI $\dagger$ ) and $9.30 \%$ cyclohexene conversion with $\mathrm{HA} / \mathrm{HCl}-18 \mathrm{~h}$ as catalyst and $\mathrm{O}_{2}$ as oxidant (Entry 7, Table 1), we conclude that the role of $\mathrm{Co}$ in $\mathrm{HA} / \mathrm{HCl}-18 \mathrm{~h} / \mathrm{Co}^{2+}-2: 1$ should be catalysized $\mathrm{O}_{2}$ to achieve active oxygen species. Whereas, with $\mathrm{H}_{2} \mathrm{O}_{2}$ as oxidant, the cyclohexene conversion is very low, only $25.70 \%$ and the main oxidation product is 1,2-cyclohexandiol $(98.70 \%$ selectivity), demonstrating under $\mathrm{O}_{2}$ and $30 \% \mathrm{H}_{2} \mathrm{O}_{2}$, cyclohexene oxidation catalyzed by $\mathrm{HA} / \mathrm{HCl}-18 \mathrm{~h} / \mathrm{Co}^{2+}-2: 1$ undergoes different pathway. Considering the facilitation of later purification and allylic products as the main oxidation with $\mathrm{O}_{2}$ as oxidant, $\mathrm{O}_{2}$ is selected as oxidant in the current catalytic reaction system. ${ }^{27}$

In the following, the effect of solvent $\left(\mathrm{CH}_{3} \mathrm{CN}, \mathrm{CH}_{2} \mathrm{Cl}_{2}, \mathrm{THF}\right.$, $\mathrm{DMF}, n$-heptane and acetic anhydride) on the selective oxidation of cyclohexene is investigated and compared with the solvent-free reaction system. Noting: the volume of solvent is six times $(4.8 \mathrm{~mL})$ the volume of cyclohexene $(0.8 \mathrm{~mL})$ to avoid the evaporation of cyclohexene in the oxidation process. The result is in Table S6. $\dagger$ It is obvious the catalytic efficiency of the solvent-free reaction system is higher when compared with the solvent reaction system $(58.30 \%$ cyclohexene conversion and 94.03\% allylic products selectivity). It can also be observed that high polar solvents (acetic anhydride and DMF) can result in the selectivity to allylic products $(57.70 \%$ and $76.70 \%$ for acetic anhydride and DMF, respectively) decreasing and accompany the selectivity to epoxy cyclohexane (20.00\% for DMF) and 1,2cyclohexanediol (41.80\% for acetic anhydride) increasing (Table S6 in ESI $\dagger$ ). It could be under the high polar solvent, the epoxy cyclohexene and 1,2-cyclohexanediol can easily desorb from the catalyst, thus facilitating the formation of epoxy cyclohexene and 1,2-cyclohexanediol. ${ }^{27,32}$

Other reaction condition, for example, the effect of reaction temperature $\left(20-80{ }^{\circ} \mathrm{C}\right)$ and reaction time $(0-24 \mathrm{~h})$ is further investigated. It shows that the cyclohexene conversion increases significantly with the increase of reaction temperature when the reaction temperature is in the range of $20-75{ }^{\circ} \mathrm{C}$ and the conversion achieves $58.30 \%$ with $94.03 \%$ allylic products selectivity when the reaction temperature is $75{ }^{\circ} \mathrm{C}$ (Fig. S5 and Table S7 in ESI $\dagger$ ). The increase of catalytic efficiency with the reaction temperature may be ascribed to the fact high temperature can afford sufficient energy for selective oxidation of 


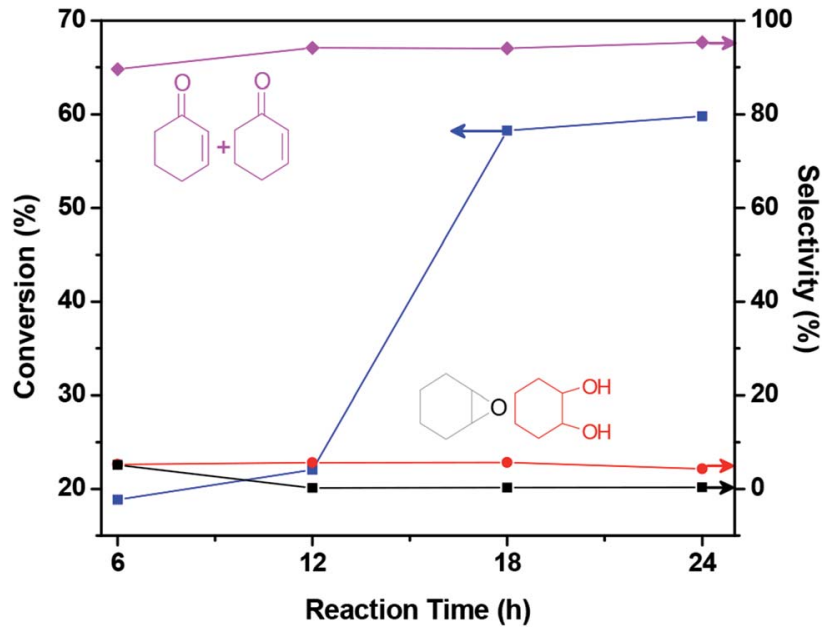

Fig. 5 The effect of reaction time on the cyclohexene conversion and selectivity of $\mathrm{HA} / \mathrm{HCl}-18 \mathrm{~h} / \mathrm{Co}^{2+}-2: 1$.

cyclohexene. ${ }^{27}$ Then the cyclohexene conversion increases indistinctly when the cyclohexene oxidation is conducted at $80{ }^{\circ} \mathrm{C}$. So $75{ }^{\circ} \mathrm{C}$ is selected as reaction temperature in the following studies. It is worth mentioning the selectivity to allylic products stays at a high level $(>90 \%)$ when the reaction temperature is at $20-80^{\circ} \mathrm{C}$. For the effect of reaction time, when the reaction time is $6 \mathrm{~h}$, the conversion is only $18.84 \%$; nevertheless when the reaction time is $18 \mathrm{~h}$, the conversion quickly increases to $58.30 \%$; with further increasing the reaction time, the conversion increases slightly (Fig. 5, Table S8 in ESI $\dagger$ ). And the selectivity to allylic products is higher than $89 \%$ within $6-$ $24 \mathrm{~h}$ reaction time, indicating during the oxidation process, the main oxidation products are allylic products. So the reaction time is fixed at $18 \mathrm{~h}$ for cyclohexene oxidation.

\subsection{Cycling stability of mesoporous etched halloysite nanotubes supported $\mathrm{Co}^{2+}$}

Stability and recycling is an important index for catalyst. ${ }^{6-15,27}$ The cycling stability experiments are conducted with $\mathrm{HA} / \mathrm{HCl}-18$ $\mathrm{h} / \mathrm{Co}^{2+}-2: 1$ as catalyst and each cycle of the reaction time is $18 \mathrm{~h}$. After each cycle, $\mathrm{HA} / \mathrm{HCl}-18 \mathrm{~h} / \mathrm{Co}^{2+}-2: 1$ is separated by centrifugation, washed by $\mathrm{CH}_{2} \mathrm{Cl}_{2}$, dried consecutively and used as catalyst for the next cycle of cyclohexene oxidation. The results are concluded in Fig. 6 and Table S9. $\dagger$ There are strong signs that cyclohexene conversion decreases slightly after four cycles, whereas allylic product selectivity demonstrates different trend, which maintains higher value $(>92 \%)$ in the first three cycles, but decrease to $35.21 \%$ in the fourth cycle. Considering the sharp declination to allylic product selectivity, we attribute it to the dissolution of $\mathrm{Co}^{2+}$ in the cycling experiment. However, it still indicates $\mathrm{HA} / \mathrm{HCl}-18 \mathrm{~h} / \mathrm{Co}^{2+}-2: 1$ can be recycled three times effectively for cyclohexene oxidation. Considering the green catalytic reaction system (solvent-free, green oxidant and simple and convenient style of adding $\mathrm{O}_{2}$ ), high allylic product selectivity and good cycling stability, it will promote to purification and has potential application prospect in the fine chemical industry.

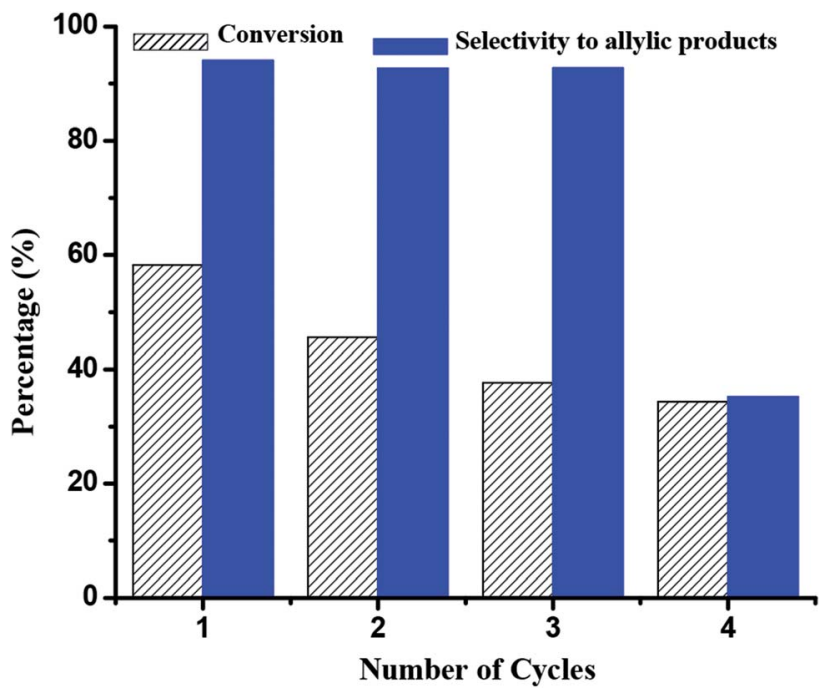

Fig. 6 The cycling stability of cyclohexene oxidation with $\mathrm{HA} / \mathrm{HCl}-18$ $\mathrm{h} / \mathrm{Co}^{2+}-2: 1$ as catalyst.

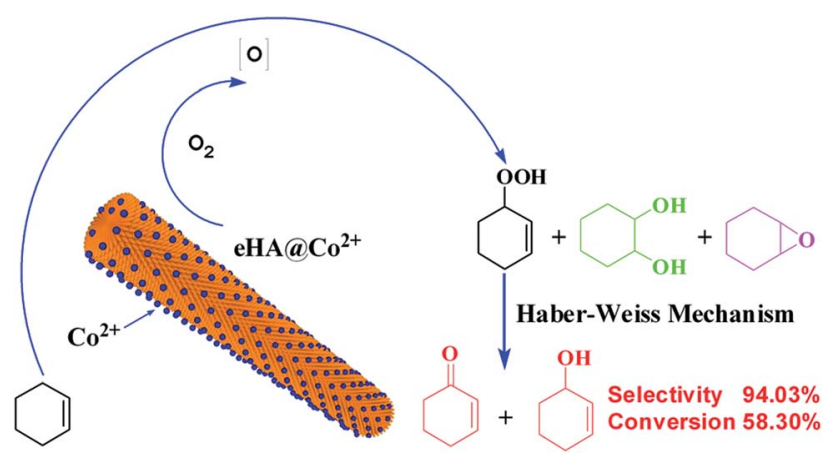

Scheme 1 Proposed mechanism of cyclohexene selective oxidation to allylic product (2-cyclohexen-1-one and 2-cyclohexen-1-ol) with mesoporous $\mathrm{eHA@C \textrm {Co } ^ { 2 + }}$ as catalyst.

\subsection{Cyclohexene selective oxidation mechanism of mesoporous etched halloysite nanotubes supported $\mathrm{Co}^{2+}$}

Based on the above results, a mechanism for the allylic oxidation of cyclohexene over mesoporous eHA supported $\mathrm{Co}^{2+}$ is proposed as follows: firstly, $\mathrm{O}_{2}$ will bind to the $\mathrm{Co}^{2+}$ in mesoporous eHA supported $\mathrm{Co}^{2+}\left(\mathrm{eHA} @ \mathrm{Co}^{2+}\right)$, leading to the form of $\mathrm{O}_{2}$-eHA@C $\mathrm{Co}^{2+}$ adduct; secondly, $\mathrm{O}_{2}$-eHA@ $\mathrm{Co}^{2+}$ adduct abstracts $\mathrm{H}$ atom from cyclohexene to form cyclohexenyl radicals and hydroperoxo complex (eHA@ $\left.\mathrm{Co}^{3+}-\mathrm{OOH}\right)$ synchronously. Then peroxy radical (HOO') will be produced by cracking the $\mathrm{Co}^{3+}-$ $\mathrm{OOH}$ bond, accompanied by the recovery of eHA@ $\mathrm{Co}^{2+}$. The peroxy radical will react with cyclohexenyl radicals to achieve 2cyclohexene-1-hydroperoxide (reaction intermediate) (Scheme 1). ${ }^{6,7}$ Finally, the formed 2-cyclohexene-1hydroperoxide will be decomposed into allylic oxidation products (2-cyclohexen-1-one and 2-cyclohexen-1-ol) according to the Haber-Weiss mechanism, which involved in the Co cycling of $\mathrm{Co}^{3+}$ and $\mathrm{Co}^{2+} \cdot 33,34$ 


\section{Conclusions}

Mesoporous eHA@ $\mathrm{Co}^{2+}$ nanotubes or nanorods have been successfully fabricated by in combination of $\mathrm{HCl}$ selective etching of interior $\mathrm{Al}_{2} \mathrm{O}_{3}$ from halloysite nanotubes and the impregnation method. Mesoporous eHA@ $\mathrm{Co}^{2+}$ endowing different BET surface area and $\mathrm{Co}^{2+}$ content can be achieved by simply tuning the etching time and the weight ratio of $\mathrm{Co}\left(\mathrm{NO}_{3}\right)_{2} \cdot 6 \mathrm{H}_{2} \mathrm{O}$ to eHA in the preparation. The mesoporous eHA@ $\mathrm{Co}^{2+}$ prepared with $18 \mathrm{~h}$ etching time and $2: 1$ $\mathrm{Co}\left(\mathrm{NO}_{3}\right)_{2} \cdot 6 \mathrm{H}_{2} \mathrm{O} / \mathrm{eHA}$ weight ratio ( $\mathrm{HA} / \mathrm{HCl}-18 \mathrm{~h} / \mathrm{Co}^{2+}-2: 1$ ) shows the highest BET surface area and high $\mathrm{Co}^{2+}$ content. The influence of etching time and $\mathrm{Co}\left(\mathrm{NO}_{3}\right)_{2} \cdot 6 \mathrm{H}_{2} \mathrm{O} / \mathrm{eHA}$ weight ratio in the fabrication of eHA@ $\mathrm{Co}^{2+}$ on the cyclohexene selective oxidation are pored through. It indicates $\mathrm{HA} / \mathrm{HCl}-18 \mathrm{~h} / \mathrm{Co}^{2+}-2: 1$ demonstrates the highest cyclohexene conversion $(58.30 \%)$ and the dominant oxidation products are 2-cyclohexen-1-one and 2cyclohexen-1-ol in solvent-free reaction system with one-time bubbled $\mathrm{O}_{2}$ as oxidants. And cyclohexene catalytic oxidation efficiency hinges on the etching time and the weight ratio of $\mathrm{Co}\left(\mathrm{NO}_{3}\right)_{2} \cdot 6 \mathrm{H}_{2} \mathrm{O}$ to eHA in the preparation. The optimal reaction condition is $75{ }^{\circ} \mathrm{C}, 18 \mathrm{~h}$, solvent-free and $\mathrm{O}_{2}$ as oxidant for cyclohexene oxidation to allylic product. According to the experiment result, a mechanism for cyclohexene oxidation attributed to reversible Co cycling between $\mathrm{Co}^{3+}$ and $\mathrm{Co}^{2+}$ in eHA@ $\mathrm{Co}^{2+}$ to catalytic formation of active [O] is suggested. This work not only provides a facilitate method to large scale synthesis of mesoporous support to achieve eHA@ $\mathrm{Co}^{2+}$ nanorods and nanotubes, which avoids the surfactant, but also affords an efficient catalyst for cyclohexene selective oxidation to allylic product. Owing to the environmentally friendly reaction system (solvent-free and one-time bubbled $\mathrm{O}_{2}$ as oxidant), this work may highlight the prospect of developing mesoporous support for $\mathrm{Co}^{2+}$ as green and recyclable heterogeneous catalysts in allylic oxidation.

\section{Conflicts of interest}

There are no conflicts to declare.

\section{Acknowledgements}

The authors gratefully acknowledge the financial support provided by the National Natural Science Foundation of China (No. 51563023 and 51003091), the Natural Science Foundation of Yunnan Province (No. 2013FB002), the Education Research Foundation of Yunnan Province (No. 2013Y361), the Program for Excellent Young Talents, Yunnan University (No. WX069051) and the Backbone Teacher Training Program of Yunnan University (No. 21132014).

\section{Notes and references}

1 Y. Cao, H. Yu, H. Wang and F. Peng, Catal. Commun., 2017, 88, 99.

2 T. Imahori, T. Tokuda, T. Taguchi and H. Takahata, Org. Lett., 2012, 14, 1172.
3 M. Sipiczki, A. A. Ádám, T. Anitics, Z. Csendes, G. Peintler, Á. Kukovecz, Z. Kónya, P. Sipos and I. Pálinkó, Catal. Today, 2015, 241, 231.

4 X. Liu and C. M. Friend, Langmuir, 2010, 26, 16552.

5 G. Yang, M. D. Huff, H. Du, Z. Zhang and Y. Lei, Catal. Commun., 2017, 99, 43.

6 Y. Fu, D. Sun, M. Qin, R. Huang and Z. Li, RSC Adv., 2012, 2, 3309.

7 D. Sun, F. Sun, X. Deng and Z. Li, Inorg. Chem., 2015, 54, 8639.

8 P. Bujak, P. Bartczak and J. Polanski, J. Catal., 2012, 295, 15.

9 Y. Cao, H. Yu, F. Peng and H. Wang, ACS Catal., 2014, 4, 1617.

10 Y. Chang, Y. Lv, F. Lu, F. Zha and Z. Lei, J. Mol. Catal. A: Chem., 2010, 320, 56.

11 A. Abdolmaleki and S. R. Adariani, Catal. Commun., 2015, 59, 97.

12 N. R. Khalili, R. Rahimi and M. Rabbani, Monatsh. Chem., 2013, 144, 597.

13 A. K. Rahiman, S. Sreedaran, K. S. Bharathi and V. Narayanan, J. Porous Mater., 2010, 17, 711.

14 E. Y. Jeong, A. Burri, S. Y. Lee and S. E. Park, J. Mater. Chem., 2010, 20, 10869.

15 C. M. Chanquia, A. L. Canepa, K. Sapag, P. Reyes, E. R. Herrero, S. G. Casuscelli and G. A. Eimer, Top. Catal., 2011, 54, 16.

16 E. Joussein, S. Petit, J. Churchman, B. Theng, D. Righi and B. Delvaux, Clay Miner., 2005, 40, 383.

17 G. J. Churchman and R. M. Carr, Clays Clay Miner., 1975, 23, 382.

18 S. Barrientos-Ramırez, E. V. Ramos-Fernandez, J. SilvestreAlbero, A. Sepulveda-Escribano, M. M. Pastor-Blas and A. Gonzalez-Montiel, Microporous Mesoporous Mater., 2009, 120, 132.

19 C. Li, X. Li, X. Duan, G. Li and J. Wang, J. Colloid Interface Sci., 2014, 436, 70.

20 C. Li, J. Wang, S. Feng, Z. Yang and S. Ding, J. Mater. Chem. A, 2013, 1, 8045.

21 E. Abdullayev, K. Sakakibara, K. Okamoto, W. Wey, K. Ariga and Y. Lvov, ACS Appl. Mater. Interfaces, 2011, 3, 4040.

22 J. Liang, B. Dong, S. Ding, C. Li, B. Q. Li, J. Li and G. Yang, J. Mater. Chem. A, 2014, 2, 11299.

23 C. Li, T. Zhou, T. Zhu and X. Li, RSC Adv., 2015, 5, 98482.

24 C. Li, J. Wang, X. Luo and S. Ding, J. Colloid Interface Sci., 2014, 420, 1.

25 C. Li, J. Wang, H. Guo and S. Ding, J. Colloid Interface Sci., 2015, 458, 1.

26 T. Zhou, C. Li, H. Jin, Y. Lian and W. Han, ACS Appl. Mater. Interfaces, 2017, 9, 6030.

27 T. Zhou, Y. Zhao, W. Han, H. Xie, C. Li and M. Yuan, J. Mater. Chem. A, 2017, 5, 18230.

28 E. Abdullayev, A. Joshi, W. Wei, Y. Zhao and Y. Lvov, ACS Nano, 2012, 6, 7216.

$29 \mathrm{H}$. W. van der Marel and H. Beutelspacher, Atlas of Infrared Spectroscopy of Clay Minerals and their Admixtures., Elsevier scientific publishing company, New York, 1976. 
30 Z. Wang, Q. Liu, J. Yu, T. Wu and G. Wang, Appl. Catal., A, 2003, 239, 87.

31 K. S. W. Sing, D. H. Everett, R. A. W. Haul, L. Moscou, R. A. Pierotti, N. Rouquerol and T. Siemieniewska, Pure Appl. Chem., 1985, 57, 603.
32 J. C. Torres, D. Cardoso and R. Pereira, Microporous Mesoporous Mater., 2010, 136, 97.

33 D. E. Hamilton, R. S. Drago and A. Zombeck, J. Am. Chem. Soc., 1987, 109, 374.

34 H. Weiner, A. Trovarelli and R. G. Finke, J. Mol. Catal. A: Chem., 2003, 191, 217. 